\title{
McKittrick-Wheelock syndrome presenting with dermatomyositis and rectal prolapse
}

This article was published in the following Dove Press journal:

Clinical and Experimental Gastroenterology

21 June 2013

Number of times this article has been viewed

\section{Mohamad Khalife' \\ Mohamad A Eloubeidi² \\ Maen Aboul Hosn' \\ 'Department of Surgery, ${ }^{2}$ Department of Internal Medicine, American \\ University of Beirut, Beirut, Lebanon}

\begin{abstract}
McKittrick-Wheelock syndrome is a rare disease characterized by a large hypersecretory rectosigmoid villous adenoma resulting in persistent large volume diarrhea, electrolyte abnormalities, and renal dysfunction. We report an unusual presentation of this syndrome in a patient who developed persistent diarrhea along with dermatomyositis and rectal prolapse and was later discovered to have a large rectal villous adenoma along with a smaller sigmoid tubulovillous adenoma. In our literature review, we were able to find one case report of a dermatomyositis occurring in conjunction with a tubulovillous adenoma and few case reports of rectal prolapse in the setting of a secretory villous adenoma. However, there were no reports on both occurring in association with McKittrick-Wheelock syndrome. This report highlights the variable manifestations of colorectal adenomas and the importance of searching for an underlying neoplastic entity in patients with new onset dermatomyositis or rectal prolapse or both.
\end{abstract}

Keywords: villous adenoma, McKittrick-Wheelock syndrome, dermatomyositis, rectal prolapse, secretory adenoma, rectal polyps

\section{Introduction}

Colonic adenomas are premalignant lesions that comprise around two thirds of all colonic polyps. ${ }^{1}$ They are usually asymptomatic, although, in some instances, they can cause rectal bleeding and some nonspecific gastrointestinal symptoms. Rarely, these adenomas can grow in size and cause hypersecretory complications such as persistent diarrhea, electrolyte imbalance, and renal failure, or what is known as McKittrick-Wheelock syndrome. ${ }^{2}$ Management of this disease consists of aggressive fluid resuscitation and correction of electrolytes as well as resection of the tumor. Dermatomyositis and rectal prolapse in association with colorectal adenomas are exceedingly rare. ${ }^{3,4}$ We found no reports in our literature review of these two entities being both present in the setting of McKittrick-Wheelock syndrome. As such we present this case as a review of this rare syndrome and to highlight this unusual presentation.

\section{Case report}

We present the case of a 69 year old Iraqi female patient who initially presented to the American University of Beirut Medical Center in February 2013 with recurrent episodes of fresh blood per rectum upon defecation. In her medical history, she reported having chronic persistent diarrhea (10 stools/24 hours) for the past 5 years. She also reported having occasional rectal prolapse (one episode every 2 weeks) over the same period as well. The patient also noted having weight loss of $10 \mathrm{~kg}$ over the past year. Her past medical history included dermatomyositis, diagnosed 4 years ago in Iraq for
Correspondence: Maen Aboul Hosn Department of General Surgery, American University of Beirut, POBox II-0236/Department of Surgery, Riad El-Solh/Beirut II07 2020 Lebanon

Emailma198@aub.edu.lb 
which the patient was on an oral steroid, and a history of left lower extremity deep vein thrombosis for which the patient was taking warfarin. Her past surgical history included right modified radical mastectomy for right breast cancer around 10 years ago. In the emergency department, the patient appeared dehydrated with dry mucous membranes. She had a soft abdomen and a digital rectal exam done at the time was negative. Her blood tests revealed a picture of prerenal azotemia with blood-urea-nitrogen-to-creatinine (BUN/ $\mathrm{Cr}$ ) ratio of 47 along with hyponatremia, hypokalemia, and hypochloremia (Table 1). She received intravenous (IV) hydration and stool studies were taken. No infectious or endocrinologic etiology for her persistent diarrhea was found so she was scheduled for colonoscopy. The colonoscopy done 2 days later revealed an ulcerated nearly obstructing mass $10 \mathrm{~cm}$ from the anal verge and another $2 \mathrm{~cm}$ polyp $30 \mathrm{~cm}$ from the anal verge (Figure 1A and B). An endoscopic ultrasound done in the same setting showed a hyperechoic mass invading the muscularis propria with no enlarged perirectal lymph nodes. She was staged as T2N0 (Figure 2). She underwent a computed tomography (CT) scan of her chest and abdomen as part of her metastatic workup which showed the mass to be a large exophytic enhancing mass in the rectosigmoid colon with well delineated lobular contour and central feeding arterial branches highly suggestive of villous adenoma (Figure 3). It was seen extending inferiorly into the anus along the mucosal lining. There was no evidence of any metastatic lesions. She was scheduled for surgical resection of the mass but she had persistent refractory hypokalemia and hypochloremia. Her electrolyte imbalances were corrected aggressively and she underwent open low anterior resection with primary anastomosis. Her final pathology report came

Table I Pertinent laboratory values on admission

\begin{tabular}{ll}
\hline White cell count & $16,400 / \mathrm{mm}^{3}$ \\
Hemoglobin & $14.8 \mathrm{~g} / \mathrm{dL}$ \\
Hematocrit & $43 \%$ \\
Platelets & $336 / \mathrm{mm}^{3}$ \\
BUN & $43 \mathrm{mg} / \mathrm{dL}$ \\
Creatinine & $0.9 \mathrm{mg} / \mathrm{dL}$ \\
Sodium & $133 \mathrm{mmol} / \mathrm{L}$ \\
Potassium & $3.1 \mathrm{mmol} / \mathrm{L}$ \\
Chloride & $88 \mathrm{mmol} / \mathrm{L}$ \\
HCO & $28 \mathrm{mmol} / \mathrm{L}$ \\
INR & 1.2 \\
PTT & $31 \mathrm{~seconds}$ \\
TSH & $1.8 \mu \mathrm{U} / \mathrm{mL}$ \\
CPK & $39 \mathrm{IU} / \mathrm{L}$ \\
\hline Abbrevition
\end{tabular}

Abbreviations: BUN, blood urea nitrogen; CPK, creatine phosphokinase; INR, international normalized ratio; PTT, partial thromboplastin time; TSH, thyroidstimulating hormone; $\mathrm{HCO}_{3}$, bicarbonate level.

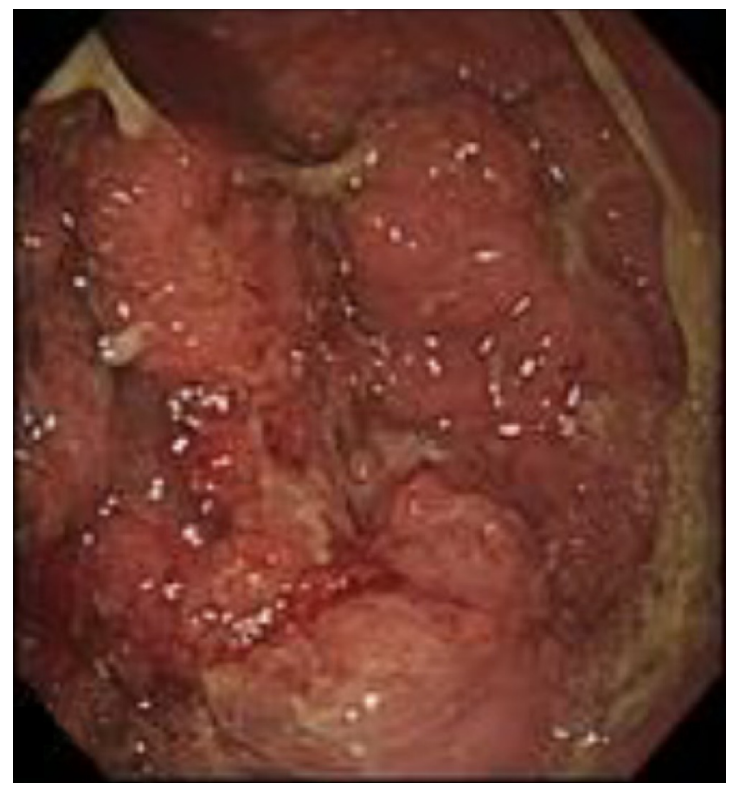

Figure I (A) Colonoscopy showing ulcerated nearly obstructing mass $10 \mathrm{~cm}$ from the anal verge.

out as large villous adenoma $(12 \mathrm{~cm})$ and tubulovillous adenoma $(5 \mathrm{~cm})$, both of which were negative for invasive carcinoma (Figure 4). She had a smooth postoperative course and was discharged home 6 days later.

\section{Discussion}

About two-thirds of all colonic polyps are adenomas. They occur in about $25 \%$ to $30 \%$ of patients over the age of $50 .{ }^{1}$ They are pathologically classified as tubular, tubulovillous, or villous adenomas. Tubular adenomas comprise

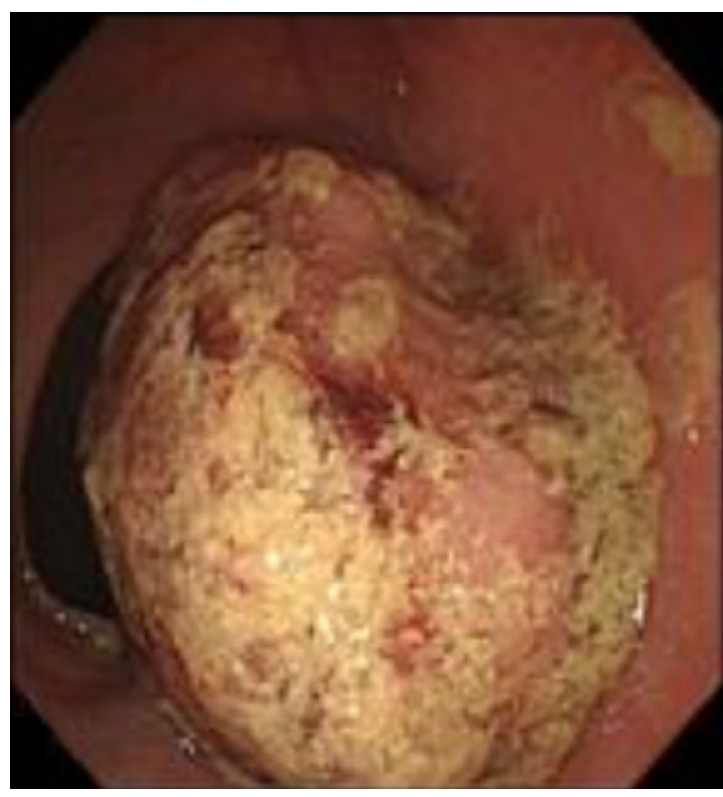

Figure I (B) Two centimeter polyp $30 \mathrm{~cm}$ from the anal verge. 


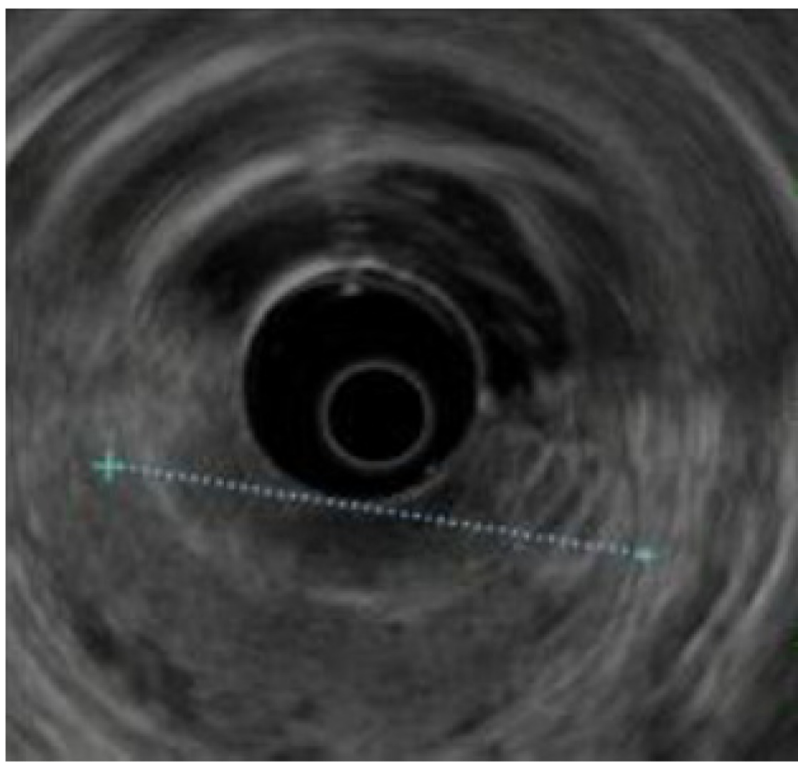

Figure 2 Endoscopic ultrasound showing a hyperechoic mass invading the muscularis propria.

around $85 \%$ of all adenomas with a $5 \%$ risk of harboring malignancy, whereas villous adenoma constitute around $5 \%$ of adenomas with a $40 \%$ estimated risk of malignancy. ${ }^{5}$ Colorectal adenomas are premalignant; however less than $5 \%$ of adenomas progress to cancer. Studies have shown that the time for an adenoma to progress into cancer ranges between 7 and 10 years. ${ }^{1}$ Risk factors for high grade dysplasia and malignant transformation include increased polyp size $(>1 \mathrm{~cm})$, multiple polyps, and villous histology. Colorectal polyps greater than $1 \mathrm{~cm}$ in diameter with a villous component or severe dysplasia are termed advanced colorectal adenomas (ACA). ${ }^{6}$ The prevalence of ACA is low. In a meta-analysis of average risk individuals, the prevalence was 3.8 percent in patients under age 65 and

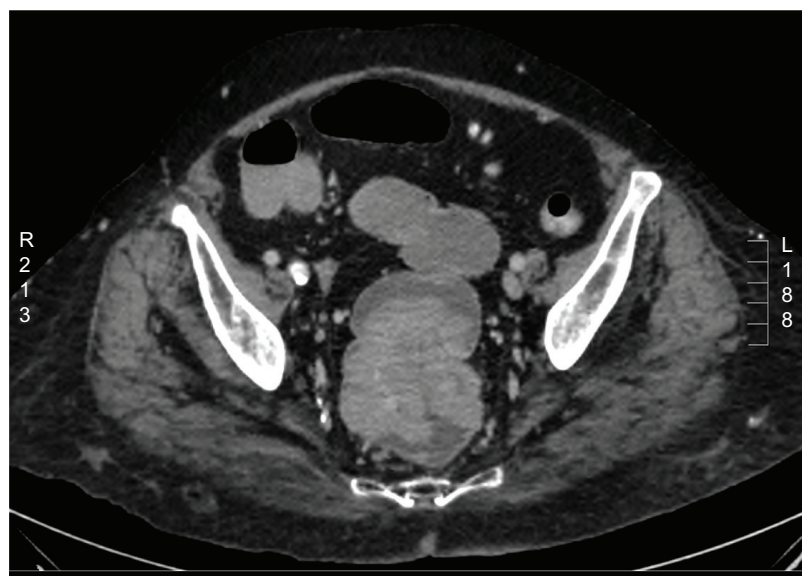

Figure 3 Computed tomography scan showing large exophytic enhancing mass in the rectosigmoid colon.

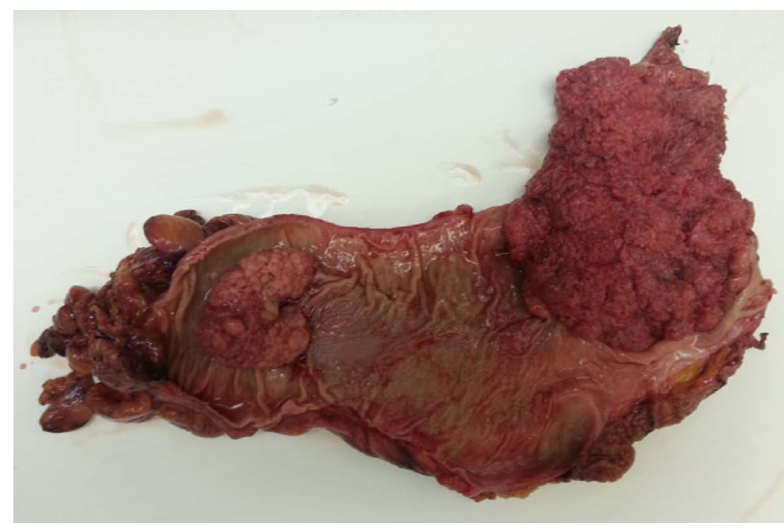

Figure 4 Specimen resected showing a $12 \mathrm{~cm}$ rectal villous adenoma and a $4 \mathrm{~cm}$ sigmoid tubulovillous adenoma.

8.2 percent in older patients. ${ }^{1}$ ACA are also associated with synchronous colonic neoplasm. Rectosigmoid ACA in particular have been shown to be associated with proximal ACA, as was the case in our patient. ${ }^{7}$ Even large adenomas, however, do not universally develop into carcinoma. ${ }^{8}$ This was clearly demonstrated in our case. Such large villous adenoma may, however, cause two important complications: either obstruction or electrolyte imbalance or both. About $2 \%$ of patients with rectosigmoid villous adenoma develop hypersecretory complications. ${ }^{9}$ The epithelial architecture of secretory adenomas has been shown to be composed largely of mucin-secreting goblet cells. Moreover, segments of intestine affected by villous adenomas have been found to secrete water, sodium, and potassium. The distal location of these lesions does not allow for fluid absorption from remaining normal colonic mucosa. ${ }^{10}$ All of these factors contribute to the large volume diarrhea, dehydration, renal dysfunction, and severe electrolyte derangements known as McKittrick-Wheelock syndrome. ${ }^{2}$ Our patient satisfied the criteria of this syndrome since she presented with large volume secretory diarrhea and was found on admission to have prerenal azotemia with marked electrolyte dysfunction. The causative lesion in McKittrick-Wheelock syndrome is usually in the rectosigmoid and is normally over $4 \mathrm{~cm}$ in diameter. ${ }^{11}$ Untreated secretant villous adenomas show a mortality of $100 \%{ }^{12}$ As such, aggressive fluid resuscitation and correction of electrolytes is mandatory prior to resection of the tumor. Resection of favorable lesions can be done endoscopically, while surgical resection is reserved for large or circumferential lesions or adenomas containing invasive cancer.

Dermatomyositis and rectal prolapse in the setting of this syndrome are very unusual. These two conditions are directly related to our patient's villous adenoma as they both occurred 
after her symptoms started 5 years ago. Dermatomyositis which is a rare inflammatory myopathy manifested by cutaneous manifestation and proximal muscle weakness has been shown to occur as a paraneoplastic manifestation of occult internal malignancy. ${ }^{13-15}$ Moreover, recent data suggest a strong correlation between dermatomyositis-associated autoantibodies against TIF1- $\gamma$, which plays an important role in cell proliferation, development and apoptosis, and cancer development. ${ }^{16}$ It has also been described in the literature in association with colorectal cancers. ${ }^{17}$ In some studies, dermatomyositis has been reported to occur up to 4 years prior to the development of malignancy. ${ }^{18}$ However, in our literature review, we could find only one case report of a benign tubulovillous adenoma associated with dermatomyositis, which ultimately resolved after resection of the adenoma. ${ }^{3}$

Rectal prolapse represents full thickness protrusion of the rectum through the anal sphincter mechanism and it has an incidence between $0.25 \%$ to $0.42 \%$ in the adult population. ${ }^{19}$ Although chronic diarrhea is a risk factor for the development of rectal prolapse, there are case reports of large villous adenomas causing rectal prolapse. ${ }^{4}$ Few cases have even been reported with giant villous adenomas causing incarceration of the prolapse. ${ }^{20,21}$ Rectal prolapse has also been associated with colorectal cancer. Rashid et al reported a retrospective study of 70 patients with rectal prolapse in which the prevalence of rectosigmoid was $5.7 \% .{ }^{22}$ Also, patients with rectal prolapse were found to have a 4.2 -fold increased risk of developing colorectal cancer compared with the control group. ${ }^{22}$

In conclusion, secretory villous adenomas should be part of the differential in patients with unexplained chronic diarrhea and electrolyte abnormalities. Moreover, new onset dermatomyositis or rectal prolapse of unknown etiology should prompt the investigation for an underlying neoplastic condition.

\section{Consent}

Written informed consent was obtained from the patient for publication of this case report and accompanying images. A copy of the written consent is available for review by the Editor-in-Chief of this journal.

\section{Disclosure}

The authors report no conflicts of interest in this work.

\section{References}

1. Heitman SJ, Ronksley PE, Hilsden RJ, Manns BJ, Rostom A, Hemmelgarn BR. Prevalence of adenomas and colorectal cancer in average risk individuals: a systematic review and meta-analysis. Clin Gastroenterol Hepatol. 2009;7(12):1272-1278.

2. McKittrick LS, Wheelock FC Jr. Carcinoma of the Colon. Springfield, IL: Charles C Thomas; 1954:61.

3. Badr AS, Saadeh CK, Yeary J, Hamous J, Khandheria B. Dermatomyositis in association with tubulovillous adenoma: resolution after resection of adenoma. South Med J. 1997;90(3):321-324.

4. Kissin MW, Wilkins RA. Complete prolapse of a massive rectal villous adenoma. Br J Radiol. 1985;58(685):87-88.

5. O'Brien MJ, Winawer SJ, Zauber AG, et al. The National Polyp Study. Patient and polyp characteristics associated with high-grade dysplasia in colorectal adenomas. Gastroenterology. 1990;98(2):371-379.

6. Zarchy TM, Ershoff D. Do characteristics of adenomas on flexible sigmoidoscopy predict advanced lesions on baseline colonoscopy? Gastroenterology. 1994;106(6):1501-1504.

7. Schoen RE, Corle D, Cranston L, et al. Is colonoscopy needed for the nonadvanced adenoma found on sigmoidoscopy? The Polyp Prevention trial. Gastroenterology. 1998;115(3):533-541.

8. Schoen RE, Papachristou GI. Screening intervals for colonic neoplasia. Curr Opin Gastroenterol. 2003;19(1):51-56.

9. Pheils MT. Villous tumors of the rectum. Dis Colon Rectum. 1979;22(6): 406-407.

10. Older J, Older P, Colker J, Brown R. Secretory villous adenomas that cause depletion syndrome. Arch Intern Med. 1999;159(8):879-880.

11. Popescu A, Orban-Schiopu A, Becheanu G, Diculescu M. McKittrickWheelock syndrome - a rare cause of acute renal failure. Rom J Gastroenterol. 2005;14(1):63-66.

12. Emrich J, Niemeyer C. The secreting villous adenoma as a rare cause of acute renal failure. Med Klin (Munich). 2002;97(10):619-623. German.

13. Sigurgeirsson B, Lindelöf B, Edhag O, Allander E. Risk of cancer in patients with dermatomyositis or polymyositis. A population-based study. N Engl J Med. 1992;326(6):363-367.

14. Buchbinder R, Forbes A, Hall S, Dennett X, Giles G. Incidence of malignant disease in biopsy-proven inflammatory myopathy a populationbased cohort study. Ann Intern Med. 2001;134(2):1087-1095.

15. Stockton D, Doherty VR, Brewster DH. Risk of cancer in patients with dermatomyositis or polymyositis, and follow-up implications: a Scottish population-based cohort study. Br J Cancer. 2001;85(1):41-45.

16. Fiorentino D, Casciola-Rosen L. Autoantibodies to transcription intermediary factor 1 in dermatomyositis shed insight into the cancermyositis connection. Arthritis Rheum. 2012;64(2):346-349.

17. Zhang W, Jiang SP, Huang L. Dermatomyositis and malignancy: a retrospective study of 115 cases. Eur Rev Med Pharmacol Sci. 2009; 13(2):77-80.

18. Wakata N, Kurihara T, Saito E, Kinoshita M. Polymyositis and dermatomyositis associated with malignancy: a 30-year retrospective study. Int J Dermatol. 2002;41(11):729-734.

19. Patel SM, Lembo AJ. Constipation: Rectal prolapse and solitary rectal ulcer syndrome. In: Feldman M, editor. Sleisenger and Fordtan's Gastrointestinal and Liver Disease, 8th ed. Philadelphia: Saunders Elsevier; 2006;1:230.

20. Shah PR, Joseph A, Haray PN, Kiberu S. Giant villous adenoma in an incarcerated rectal proplapse: a clinical conundrum! Indian J Surg. 2005;67(2):100-101.

21. Pinto AC, Desa LA, Pyasi RR, D'Sousa FH. Giant tubulovillous adenoma of rectum presenting as rectal prolapsed. Bombay Hospital Journal. 2008;50(4):646-647.

22. Rashid Z, Basson MD. Association of rectal prolapse with colorectal cancer. Surgery. 1996;119(1):51-55. 
Clinical and Experimental Gastroenterology

Dovepress

\section{Publish your work in this journal}

Clinical and Experimental Gastroenterology is an international, peerreviewed, open access journal, publishing all aspects of gastroenterology in the clinic and laboratory, including: Pathology, pathophysiology of gastrointestinal disease; Investigation and treatment of gastointestinal disease; Pharmacology of drugs used in the alimentary tract;

Immunology/genetics/genomics related to gastrointestinal disease. This journal is indexed on CAS. The manuscript management system is completely online and includes a very quick and fair peer-review system. Visit http://www.dovepress.com/testimonials.php to read real quotes from published authors.

Submit your manuscript here: http://www.dovepress.com/clinical-and-experimental-gastroenterology-journal 